\title{
Effect of Different Sowing Dates on Pest Incidence in Chickpea
}

\author{
T. Pavani ${ }^{1,3}$, T. Ramesh Babu' ${ }^{2}$, D. Sridevi ${ }^{3}$, K. Radhika ${ }^{2}$ and H.C. Sharma ${ }^{1,4 *}$ \\ ${ }^{1}$ International Crops Research Institute for the Semi-Arid Tropics (ICRISAT), Patancheru \\ 502324, Hyderabad, Andhra Pradesh, India; \\ ${ }^{2}$ Acharya N.G. Ranga Agricultural University (ANGRAU), Rajendranagar 500030, \\ Hyderabad, Andhra Pradesh, India \\ ${ }^{3}$ Professor Jayashankar Telangana State Agricultural University (PJTSAU) Rajendranagar \\ 500030, Hyderabad, Telangana, India \\ ${ }^{4}$ YSP University of Horticulture \& Forestry, Nauni 173230, Solan, Himachal Pradesh, India \\ *Corresponding author
}

\section{A B S T R A C T}

\begin{tabular}{|l|}
\hline K e y w o r d s \\
Chickpea, \\
Climate change, \\
Pest incidence, \\
Helicovepa \\
armigera, \\
Spodoptera exigua, \\
Campoletis \\
chlorideae
\end{tabular}

\section{Introduction}

Chickpea (Cicer arietinum L.) also known as Bengal gram or gram, is the second most important food legume in Asia, North Africa, and Mexico. Recently, it has also become an important grain legume crop in North USA, Canada, and Australia. It is grown on 13.5 million hectares worldwide, with an average
Global warming and climate change will have a major bearing on pest incidence and pest associated losses in field crops. Therefore, we studied pest incidence in chickpea across sowing dates to understand the effect of climatic factors on pest incidence on five genotypes of chickpea. The egg laying by the pod borer, Helicoverpa armigera decreased across sowing dates from October to December, with a slight increase in oviposition was observed in the January sown crops. ICC 3137 was most preferred for egg laying (9.5 eggs/5 plants), followed by KAK 2 (6.8 eggs/5 plants). The incidence of $H$. armigera decreased with a delay in time of sowing (60.0 larvae/5plants in the October sown crop to 21.9 larvae/5plants in the December sown crop). However, a slight increase was observed in the January sown crop (34.8 larvae/5plants). The highest incidence of $H$. armigera larvae was recorded on ICC 3137 (55.1 larvae/5plants), and the lowest on ICCV 10 (29.9 larvae/5plants). 
and Yadav et al., 2006; Sharma et al., 2011). Losses due to insect pest damage are likely to increase as a result of changes in cropping patterns, and global warming.

The pod borer, Helicoverpa armigera (Hubner), is one of the most important constraints in chickpea production (Sharma, 2005). Its population peaks generally correspond to the full bloom and pod formation stage of the crop in the post rainy season. Temperature, relative humidity (Yadava and Lal 1988, Yadava et al., 1991), rainfall (Tripathi and Sharma 1985), predators (Thakur et al., 1995, Gunathilagaraj 1996) and parasitoids (Bhatnagar 1980, Srinivas and Jayaraj 1989, Thakur et al., 1995) affect the incidence and population densities of $H$. armigera on chickpea. Information on pest incidence under field conditions across sowing dates can be used to assess the effect of different climatic variables on pest incidence and grain yield. Therefore, we studied the effect of climatic factors on pest incidence and grain yield on five genotypes of chickpea.

\section{Materials and Methods}

Five chickpea genotypes ( 2 resistant - ICCL 86111 and ICCV 10, 2 commercial cultivars JG 11 and KAK 2, and 1 susceptible genotype - ICC 3137) were sown across four planting dates between October - January at monthly intervals during 2012 - 14 post rainy seasons under field conditions. The experiment was laid out in randomized complete block design (RCBD) with three replications for each genotype, in a plot of four rows $2 \mathrm{~m}$ long (with a spacing of $60 \mathrm{~cm}$ between the rows and $10 \mathrm{~cm}$ between plants with in a row). Data were recorded on numbers of insects/plant. at fortnightly intervals in each planting. Data were also recorded on leaf feeding (leaf damage rating on a 1 to 9 scale $(1=<10 \%$ leaf area damaged, and $9=>80 \%$ leaf area damaged) (Sharma et al., 2005). The incidence/abundance of different insect pests was correlated with the climatic factors (average temperature, open pan evaporation, rainfall, sunshine hours, solar radiation, wind velocity, and relative humidity during the observation period). The crop was raised under normal agronomic practices, and there was no insecticide application in the experimental plots.

Weather data during the experimental period was obtained from the agro meteorology station at the ICRISAT farm. Data on rainfall, temperature, relative humidity, open pan evaporation, sunshine hours, solar radiation and wind velocity during the experimental period was correlated with lead damage, and egg and larval density (Incidence) during the experimental period.

\section{Results and Discussion}

Oviposition by $H$. armigera females on different genotypes of chickpea

There were significant differences in the numbers of $H$. armigera eggs across different dates of sowing in both the seasons, as well as across the seasons. The egg laying by the $H$. armigera females decreased as the sowing dates advanced from October to December (19.9 - 5.2 eggs/5 plants in 2012/13; 9.2 - 3.7 eggs/5 plants in 2013/14 and $13.9-4.3$ eggs/5 plants across the seasons), but a slight increase in oviposition was recorded in the January sown crop (5.9 eggs/5 plants in $2012-13,4.3$ eggs/5 plants in 2013 - 2014, and 5.1 eggs/5 plants across the seasons). More number of eggs were recorded in 2012 -13 than in 2013 -14 . Highest numbers of eggs were observed in the crop sown in October in both the seasons.

There were significant differences in oviposition on different genotypes across sowing dates, and the interaction effects were nonsignificant. Among the genotypes tested, 
ICC 3137 had the highest number of eggs across the seasons (11.3 eggs/5 plants, in 2012 - 13; 7.7 eggs/ 5 plants in 2013 - 14 and 9.5 eggs/5 plants across the seasons), while the oviposition was recorded on JG 11 (6.3 eggs/ 5 plants) in $2012-13$, and on ICCV 10 and ICCL 86111 (3.5 eggs/ 5 plants) in 2013 - 14. Across seasons, ICC 3137 was most preferred for egg laying (9.5 eggs/5 plants), followed by KAK 2 (6.8 eggs/5 plants). ICCV 10 and JG 11 (5.9 eggs/5 plants) were relatively nonpreferred for egg laying (Fig. 1).

Variation in density of $\boldsymbol{H}$. armigera larvae on different genotypes of chickpea across sowings

The incidence of $H$. armigera larvae was highest in the crop sown in October (80.7 larvae/5plants), and lowest in the December sown crop (20.1 larvae/5plants) in $2012-13$. In the 2013 - 14 cropping season, the incidence of $H$. armigera was quite high in the crop sown in November (40.7 larvae/5plants), October (39.3 larvae/5plants) and January (38.3 larvae/5plants), but low in the December sown crop (23.8 larvae/5 plants). Across seasons, the incidence of $H$. armigera declined as the sowing date was advanced from October (60.0 larvae/5plants) to December (21.9 larvae/5plants), but increased in the January sown crop (34.8 larvae/5 plants).

There were significant differences in numbers of $H$. armigera larvae across genotypes in both the seasons, but the interaction effects were nonsignificant. Highest number of $H$. armigera larvae were recorded on ICC 3137 (51.9 larvae/5plants), followed by KAK 2 (46.6 larvae/5plants) and ICCL 86111 (41.8 larvae/5plants). The lowest incidence of $H$. armigera larvae was recorded in ICCV 10 (28.2 larvae/5plants), followed by JG 11 (38.3 larvae/5plants). In 2013 - 14 post rainy seasons, the $H$. armigera larval density was significantly higher on ICC $3137 \quad$ (58.3 larvae/5plants) and KAK $2 \quad$ (37.9 larvae/5plants) than on ICCV $10 \quad(31.7$ larvae/5plants), JG 11 (30.1 larvae/5plants and ICCL 86111 (24.7 larvae/5plants). Across seasons, highest incidence was recorded on ICC 3137 (55.1 larvae/5plants), and the lowest on ICCV 10 (29.9 larvae/5plants). The larval density decreased from October to December, but a slight increase was observed in the crop sown in January. Across seasons, lowest larval density was recorded on ICCV 10 (15.5 larvae/5plants) in the December sown crop, and highest on ICC 3137 (84.6 larvae/5plants) in the October sown crop (Fig. 2).

Oviposition by beet armyworm, S. exigua on different genotypes of chickpea

There were no significant differences in the numbers of $S$. exigua egg masses across the sowings in the 2012 - 13 cropping season. No egg masses were observed in the October sown crop in 2012 - 13. Highest egg laying was recorded in the January sown crop (0.4 egg masses/5 plants). The number of egg masses differed significantly across sowing dates in the 2013 - 14 cropping season. In 2013 - 14, significantly highest numbers of egg masses were recorded in the December sown crop (1.3 egg masses/5 plants), but the differences in egg laying were nonsignificant in the crops sown in October, November and January. Similar trend was observed across seasons. The highest numbers of egg masses were recorded in the December sown crop (0.7 egg masses/5 plants), and greater egg laying was recorded in 2013-14 than in 2012 - 13 cropping season.

No egg laying was observed on ICCL 86111, while a fewer egg masses were recorded on ICCV 10 (0.3 egg masses/ 5plants) in the January sown crop, and in JG 11 in the November and January sown crops. The number of egg masses deposited on different genotypes differed significantly during the 
2013 - 14 cropping season, and highest number of egg masses (1.7 egg masses/5 plants) were recorded on KAK 2, while no eggs were recorded in ICCV 10. Across seasons, highest number of $S$. exigua egg masses (1.0 egg masses/5 plants) were recorded on KAK 2, followed by ICC 3137 (0.4 egg masses/5 plants) and ICCL 86111 (0.4 egg masses/5 plants). The interaction effects were non - significant across the seasons. No egg masses were recorded in the October sown crop in both the seasons, except on KAK 2 in the $2013-14$ cropping season (Fig. 3).

Population of beet armyworm, S. exigua larvae on different chickpea genotypes

In the $2012-13$ cropping season, the numbers of $S$. exigua larvae were highest in the crop sown in January (16.1 larvae/5plants), followed by the December (11.6 larvae/5plants), November larvae/5plants) and October (4.7 larvae/5plants) sown crops. During the 2013 14 cropping season, the numbers of $S$. exigua larvae were significantly higher in the crop sown in January (15.5 larvae/5plants), followed by the December sown crop (11.6 larvae/5plants). Significantly lower larval population was recorded in the November (1.3 larvae/5plants) and October (2.0 larvae/ 5plants) sown crops. Across the seasons, the $S$. exigua incidence was significantly greater in the January sown crop (15.8 larvae/5plants) than in the crops sown in October, November and December. The January sown crop was most affected by $S$. exigua larvae in both the cropping seasons, as the crop grew and matured during the warm months of February to May. The larval incidence was comparatively greater in the 2013 - 14 than in 2012 - 13 cropping season.

There were no significant differences in the numbers of $S$. exigua larvae on different genotypes in the $2012-13$ cropping season. KAK 2 had the maximum numbers of $S$. exigua larvae (15.6 larvae/5plants), followed by ICCL 86111 (11.6 larvae/5plants), JG 11 (9.3 larvae/5plants) and ICC 3137 (8.8 larvae/5plants). Less $S$. exigua larval numbers were recorded on ICCV $10 \quad(7.8$ larvae/5plants). During the 2013 - 14 cropping season, there were no significant differences among the genotypes tested. However, the highest numbers of $S$. exigua larvae were observed on JG 11 (12.1 larvae/5plants), followed by ICC 3137 and ICCL 86111 (5.1 larvae/5plants). Across seasons, the highest numbers of $S$. exigua larvae were recorded on KAK 2 (12.9 larvae/5plants) and lowest on ICC 3137 (7.0 larvae/5plants).

The interaction effects between the genotypes and sowing dates were not significant. The lowest (2.5 larvae/5plants) incidence was recorded in ICCV 10 in the November sown crop, and highest in KAK 2 in the January sown crop (27.2 larvae/5plants). Highest numbers of egg masses were also recorded on KAK 2 - Kabuli type genotype, suggesting that it is highly susceptible to S. exigua. KAK 2 was found to be highly susceptible to $S$. exigua, while ICC 3137 was highly susceptible to $H$. armigera. ICCV 10 was relatively resistant to both $H$. armigera and $S$. exigua. The $S$. exigua incidence was observed mostly in the early stages of the crop, irrespective of the planting dates (Fig. 4).

Variation in parasitization of $\boldsymbol{H}$. armigera by the larval parasitoid Campoletis chlorideae

During the 2012 - 13 cropping season, greater numbers of cocoons of $C$. chlorideae were observed in the December sown crop (3.4 cocoons/5plants), followed by the October sown crop (2.4 cocoons/5plants). Lowest parasitization $(0.1$ cocoons $/ 5$ plants $)$ were 
recorded in the January sown crop. In the 2013 - 14 cropping season, maximum parasatization (5.7 cocoons/5 plants) was recorded in the October sown crop, and the lowest ( 0.4 cocoons $/ 5$ plants) in the January sown crop. Across seasons, highest (4.0 cocoons/5 plants) activity of the parasitoid was recorded in the October sown crop, andthe lowest ( 0.2 cocoons $/ 5$ plants) in the January sown crop, suggesting that the parasitoid is mostly active during the cooler part of the winter season.

Fig.1 Oviposition by $H$. armigera females on different genotypes of chickpea in relation to temperature and RH under natural infestation in the field

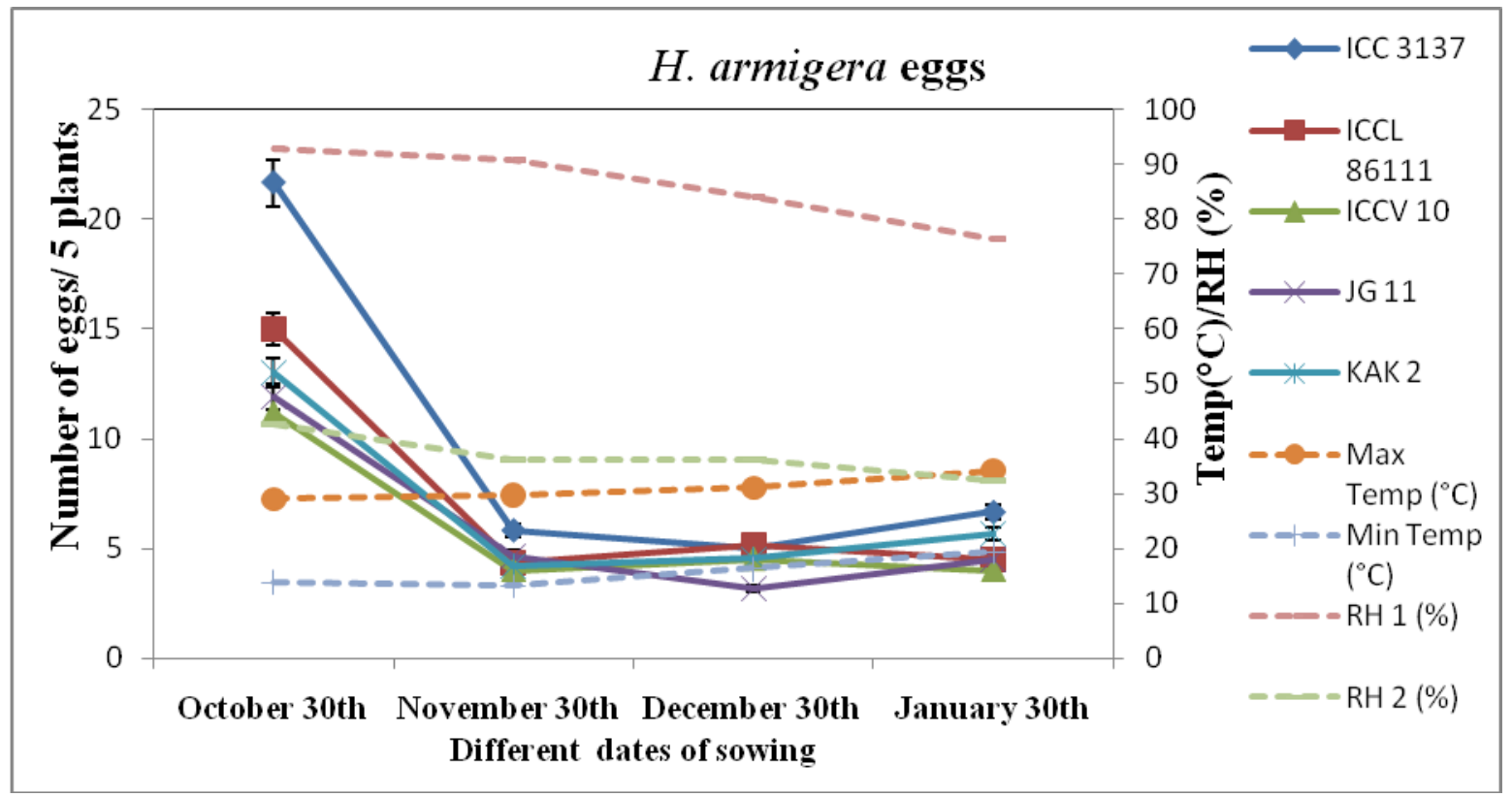

Fig.2 Abundance of $H$. armigera larvae on different genotypes of chickpea in relation to temperature and RH under natural infestation in the field

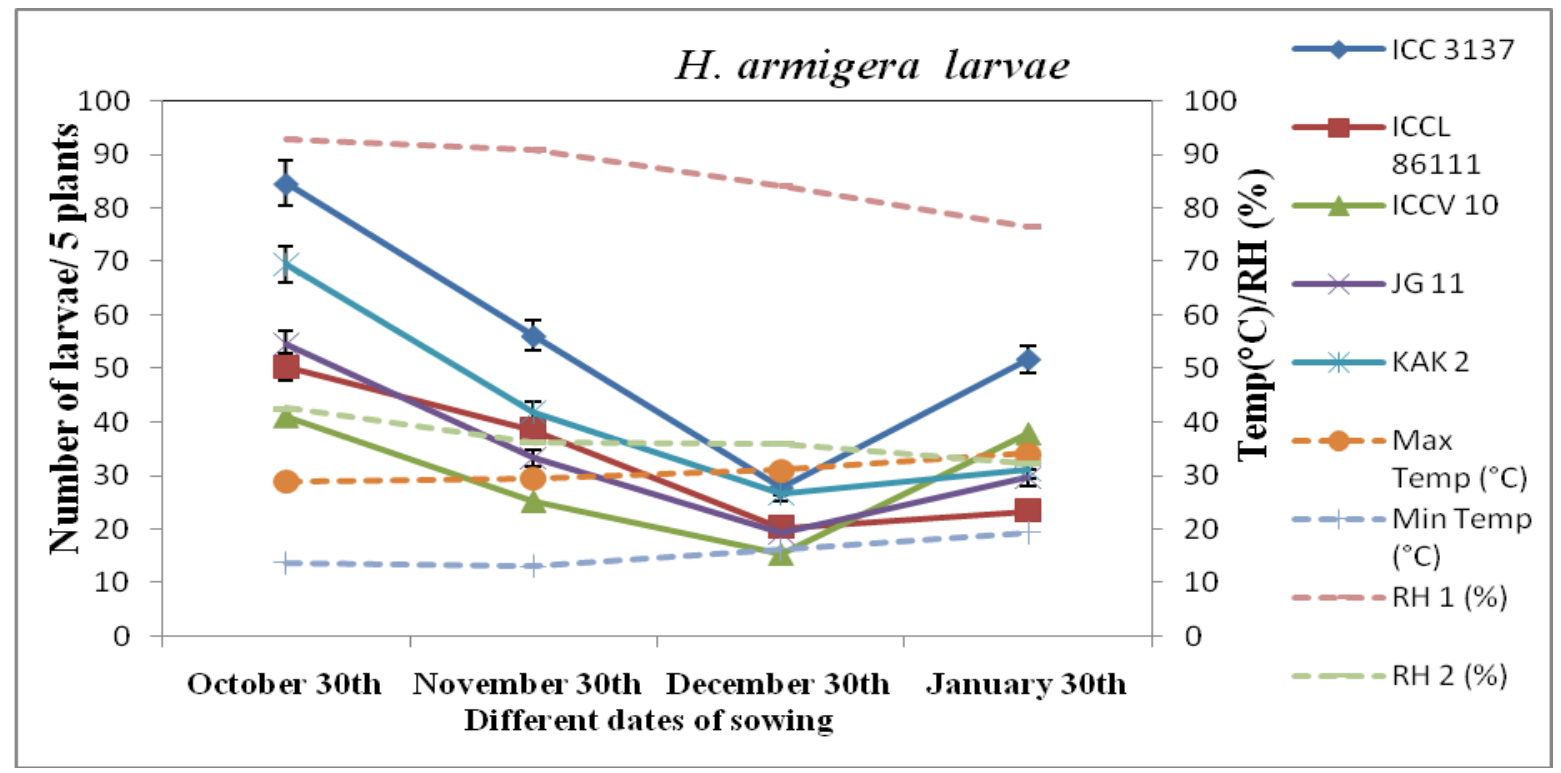


Fig.3 Oviposition by $S$. exigua females on different genotypes of chickpea in relation to temperature and $\mathrm{RH}$ under natural infestation in the field

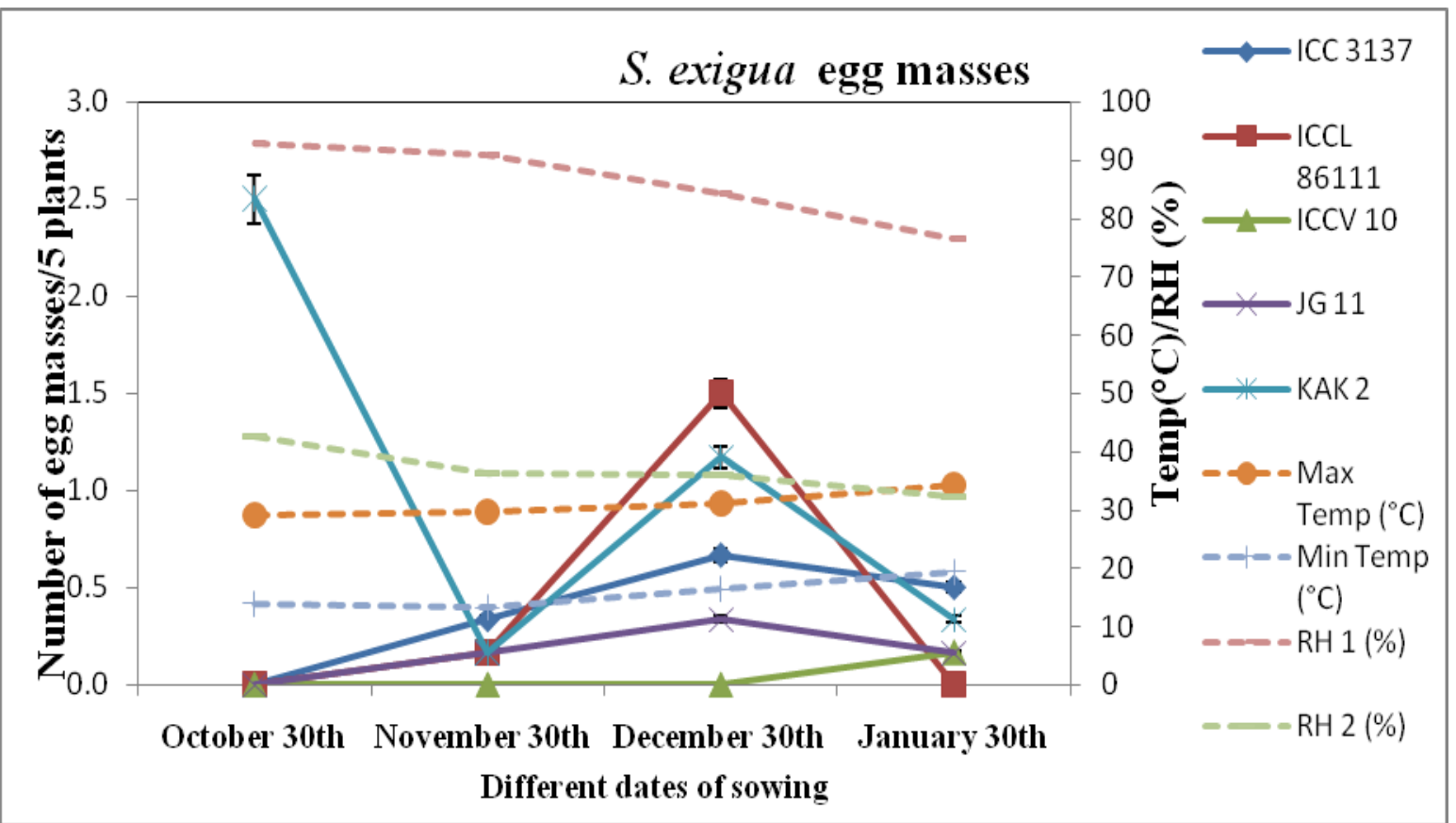

Fig.4 Abundance of S. exigua larvae on different genotypes of chickpea in relation to temperature and RH under natural infestation in the field

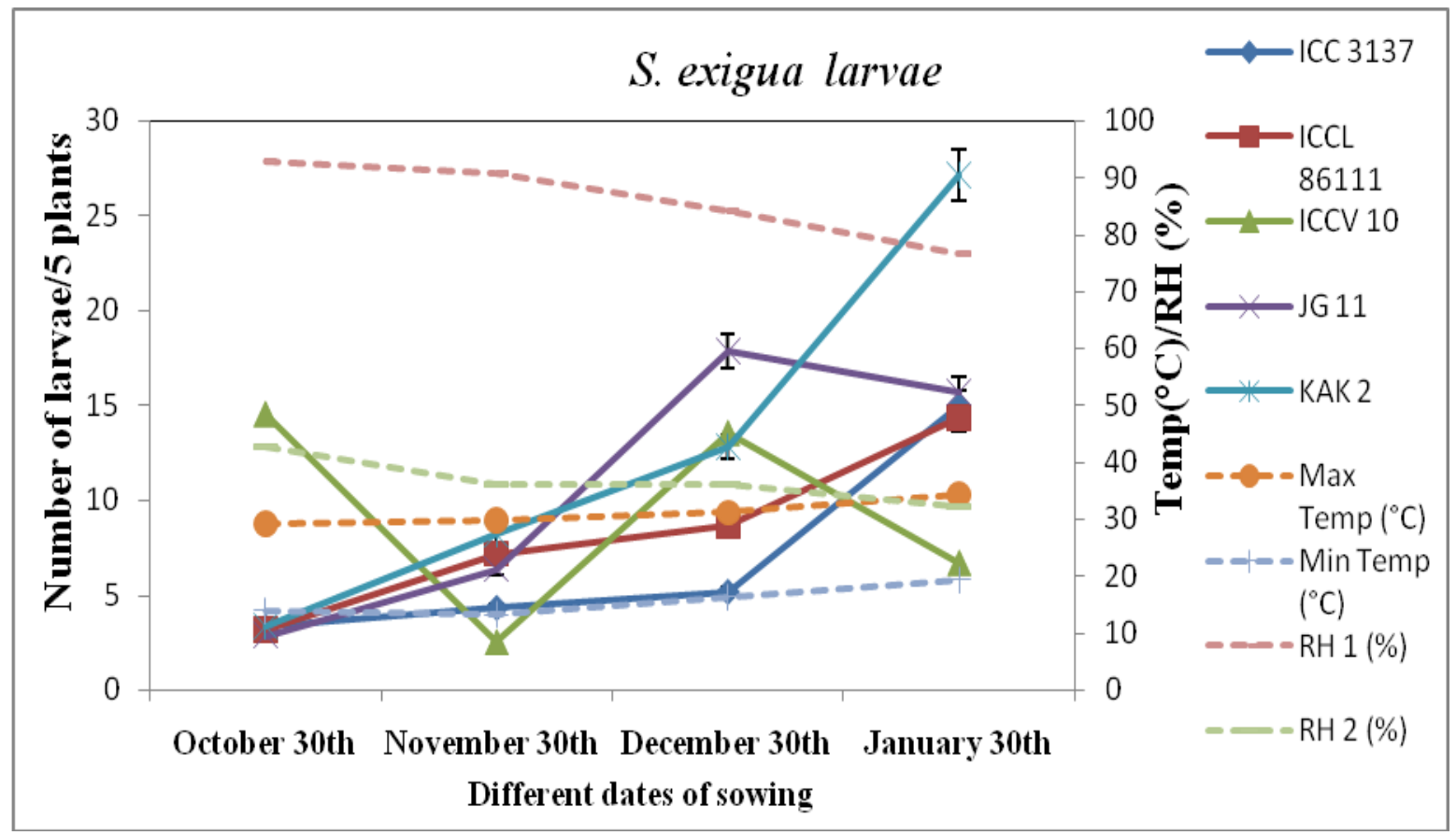


Fig.5 Numbers of $C$. chloridaea cocoons on different genotypes of chickpea in relation to temperature and $\mathrm{RH}$ under natural conditions in the field

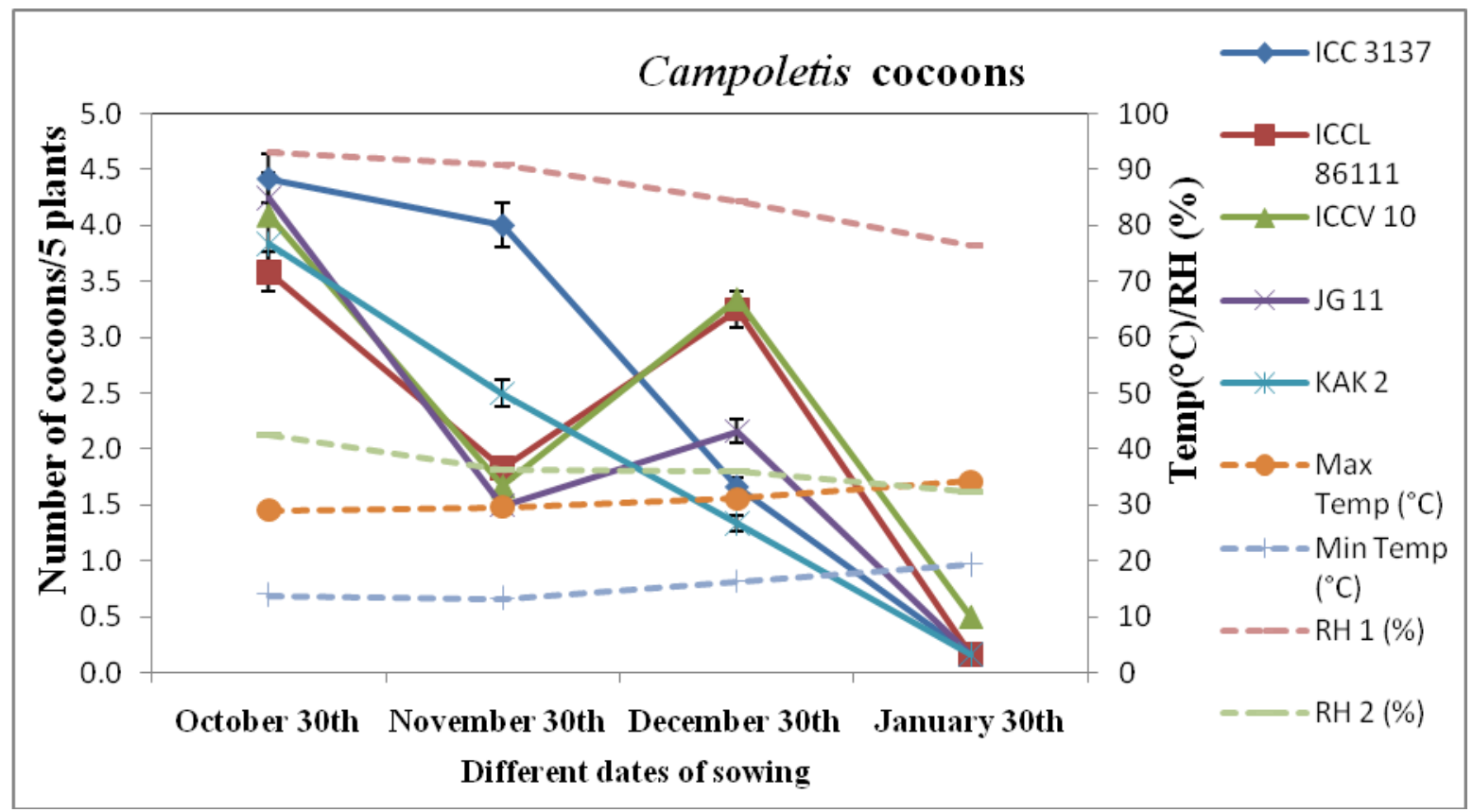

There were no significant differences in the numbers of $C$. chlorideae cocoons on different genotypes in both the seasons. However, highest numbers of cocoons were recorded on ICC 3137 (2.6 cocoons/5plants), and the lowest on KAK 2 and JG 11 (2.0 cocoons/5 plants). The interaction effects were not significant (Fig. 5).

In the early sown crop, which developed and matured during the cooler part of the post rainy season, there were significant differences in genotypic susceptibility to pod borer damage, but the differences between the genotypes were less apparent in $H$. armigera larvae in the late sown crops. Though the numbers of $H$. armigera larvae decreased with the planting dates, the extent of damage by $H$. armigera increased across the planting dates in both cropping seasons, which could be ascribed to warmer conditions during crop development and maturity. Parasitization of $H$. armigera larvae by $C$. chlorideae also decreased with the planting dates, resulting in a decreased in biological control of $H$. armigera larvae, and increased crop damage. Damage by $H$. armigera increased with an increase in temperature as a result of reduction in the dry matter and grain yield.

Shankar et al., (2014) reported that numbers of $S$. exigua and $H$. armigera larvae were maximum on ICC 3137 at the vegetative, flowering and podding stages in both the seasons, while ICCL 86111 harboured the lowest numbers of $H$. armigera and $S$. exigua larvae. More $H$. armigera moths were trapped during March to April (Mahapatra et al., 2007), and November sown crops suffered less pod damage than that sown in December (Prasad et al., (1989; Begum et al., 1992). Delayed sowing of chickpea is risky under rainfed conditions due to inadequate stored soil moisture, and increased risk of damage by $H$. armigera. (Prasad and Singh 1997). Oviposition by $H$. armigera was low in the crop sown between December to MidFebruary due to cold conditions in Pakistan (Shah and Shahzad, 2005), whereas Ali et al., (2009) observed that the numbers of eggs laid 
by $H$. armigera differed significantly across sowings on different genotypes of cotton, but there were no significant differences in larval density and damage across genotypes and sowing dates.

The $H$. armigera larval population was high in early sown crops (October $15^{\text {th }}$ to November $1^{\text {st }}$ ) than in and delayed sowings (November $1^{\text {st }}$ to $30^{\text {th }}$ ) (Anwar et al.,1994). The genotypic response to damage by $H$. amigera varies across seasons and locations (Sharma et al., 2003). The genotypes (ICC 506EB, ICC 12476, ICC 12477, ICC 12478 and ICC 12479) that are not preferred for oviposition also suffer low leaf damage by $H$. armigera (Narayanamma et al., 2007).

The abundance of $H$. armigera decreased with an increase in temperature, but plant damage increased with a rise in temperature. This may be due to better plant growth in early sowings than in the late sown crops due to inadequate soil moisture and dry weather conditions, which retarded the plant growth, with less pod setting, and consequently resulting in poor grain yield. The vegetative growth and the dry matter production decreased with an increase in temperature due to water stress.

The numbers of $C$. chlorideae cocoons decreased with an increase in temperature. Higher temperatures resulted in reduced efficacy of control agents of $H$. armigera, which may also have contributed to increase in plant damage. Patnaik and Senapati (1996) observed a negative correlation between mean temperature range and larval incidence of $H$. armigera. A positive association was observed between $H$. armigera and $S$. exigua larvae, and similar results were earlier reported by Sharma (2012b). Positive correlation has earlier been observed between $H$. armigera larval incidence and the maximum and the minimum temperatures (Sharma et al., 2005., Shah and Shahzad,
2005., Upadhyay et al., 1989; Pandey, 2012). Ugale et al., (2011) reported that moth emergence was negatively correlated with the maximum ( $\mathrm{r} \quad=-0.62)$ and minimum temperature $(\mathrm{r}=-0.75)$, but there was no association with relative humidity. Minimum temperature and rainfall exerted a negative influence on pheromone trap catches of $H$. armigera (Prasad et al., (1989) The population of $H$. armigera and $S$. exigua larvae was negatively correlated with relative humidity across genotypes. However, a significant and negative correlation has earlier been reported between $H$. armigera larval density and maximum relative humidity (Sharma et al., 2005; Upadhyay et al., 1989; Pandey, 2012 and Shah and Shahzad, 2005). Densities of eggs and of different larval instars of $H$. armigera were significantly and negatively correlated with the maximum relative humidity, but not with the minimum relative humidity. Extremes of temperature, humidity and other weather factors (e.g., wind and hailstorm) might result in mortality of eggs, larvae and pupae of most of insect species (Pearson, 1958 and Qayyum and Zalucki, 1987). Pest outbreaks are more likely to occur with stressed plants as a result of weakening of plants' defensive system, and thus, increasing the level of susceptibility to insect pests. Global warming will lead to earlier infestation by $H$. armigera in North India (Sharma, 2010a), resulting in increased crop loss. Climate change may also alter the interactions between the insect pests and their host plants (Sharma, 2014)). Relationships between insect pests and their natural enemies will change as a result of global warming, resulting in both increases and decreases in the status of individual pest species. Changes in temperature will also alter the timing of diurnal activity patterns of different groups of insects and changes in inter specific interactions could also alter the effectiveness of natural enemies for pest management (Hill and Dymock, 1989). 
Global warming and climate change will influence survival, development and population dynamics of $H$. armigera, and this will have a major bearing on extent of crop losses, and timing of different components of pest management to minimize the losses due to this pest. Future studies should focus on simultaneously testing the effects of multiple environmental factors on insect-plant interactions, to gain a realistic perspective of how global climatic changes may impact the production of secondary chemicals and its potential implications for co evolutionary associations between the interacting plant and insect species.

\section{Acknowledgements}

We thank the staff, Insect Rearing Laboratory, Entomology, for providing the insects throughout the study and PJTSAU for providing financial assistance.

\section{References}

Ali A., Aheer G. M., Saleem M., Ashfaq, M., and Khan M. A (2009) Effect of sowing dates on population development of Helicoverpa armigera (Hubner) in cotton genotypes. Pakisthan Entomology. 31(2): 128-132.

Anwar M., Shafique M., Ahmad M. and Shaloori A.P (1994) Incidence of attack and population fluctuation of Heliothis armigera in relation to chickpea phenology and environmental factors. Proceedings of Pakistan Congress of Zoology. 12.

Begum N., Husain $M$ and Chowdhury, S.I (1992) Effect of sowing date and plant density on pod borer incidence and grain yield of chickpea in Bangladesh. International Chickpea Newsletter. 27: 19-21.

Bhatnagar V. S (1980) A report on research on Heliothis complex at ICRISAT (India), 1974-79. International Crops
Research Institute for the SemiAridTropics. pp. 23.

Food and Agriculture Organization, The State of Food Insecurity in the World 2013, 2013 http://www.fao.org/docrep/013 /i1683e/i1683e.pdf.

Gunathilagaraj K (1996) Management of Helicoverpa armigera in chickpea with Acridotheres tristis. Madras Agricultural Journal. 83: 72-73.

Hill M.G and Dymock J (1989) Impact of Climate Change: Agricultural/ Horticultural Systems. DSIR Entomology Division Submission to the New Zealand Climate Change Program. Auckland, New Zealand: Department of Scientific and Industrial Research. 16 pp.

Hossain M.A., Haqueb M.A and Prodhan M.Z.H (2008) Incidence and damage severity of pod borer, Helicoverpa armigera (Hubner) in chickpea (Cicer arietinum L.). Bangladesh Journal of Scientific and Industrial Research. 44(2): 221 - 224.

IPCC (1990a) Climate change: The IPCC Scientific Assessment. Inter governmental Panel on Climate Change. Geneva and Nairobi, Kenya: World Meteorological Organization and UN Environment Program. 365 pp.

IPCC (1990b) The Potential Impacts of Climate Change on Agriculture and Forestry. Intergovernmental Panel on Climate Change. Geneva and Nairobi, Kenya: World Meteorological Organization and UN Environment Program.

Mahapatra S.D., Aswal J.S. and Mishra P.N (2007) Monitoring population dynamics of tomato fruit borer, Helicoverpa armigera (Hubner) moths through pheromone traps in Uttaranchal Hills. Indian Journal of Entomology. 69(2): 172-173.

Mahapatra S.D., Aswal J.S. and Mishra P.N 
(2007) Monitoring population dynamics of tomato fruit borer, Helicoverpa armigera (Hubner) moths through pheromone traps in Uttaranchal Hills. Indian Journal of Entomology. 69(2): 172-173.

Narayanamma V.L., Sharma H.C., Gowda C.L.L and Sriramulu M (2007a) Expression of resistance to pod borer, Helicoverpa armigera (Lepidoptera: Noctuidae) in relation to HPLC fingerprints of leaf exudates of chickpea. Ph.D thesis submitted to ANGRAU, Hyderabad, Andhra Pradesh, India.

Narayanamma V.L., Sriramulu M., Gorda C.L.L., Ghaffar M.A and Sharma H.C (2007b) Tolerance to Helicoverpa armigera damage in chickpea genotypes under natural infestation. Indian Journal of Plant Protection. 35(2): 227 $-231$

Pandey B.M., Tripathi M.K. and Vijay Lakshmi (2012) Seasonal incidence of Helicoverpa armigera on Chickpea. Annals of plant protection sciences.22(1): 190-239.

Patil S.K, Shinde G.P and Jamadagni B.M (2007) Reaction of short-duration chickpea genotypes for resistance to gram pod borer, Helicoverpa armigera in Maharashtra, India. Journal of SAT Agricultural Research. 5(1): 1 - 2.

Patil S.K, Shinde G.P and Jamadagni B.M (2007) Reaction of short-duration chickpea genotypes for resistance to gram pod borer, Helicoverpa armigera in Maharashtra, India. Journal of SAT Agricultural Research. 5(1): 1 - 2.

Patnaik H. P and Senapati B (1996) Trends in Helicoverpa egg, larval and adult population changes in the chickpea environment of Orissa. Indian Journal of Plant Protection. 24: 18-23.

Pearson E.O (1958) The Insect Pests of Cotton in Tropical Africa. London:
Common Wealth Institute of Entomology. Pages: 355.

Prasad C.S and Singh V.P (1997) Impact of variety, sowing date and control measures on incidence of pod borer, Helicoverpa armigera(Hub) and yield of chickpea. Annals of plant protection sciences: 5:26-28.

Prasad D., Chand P., Deka N. K. and Prasad $R$ (1989) Population dynamics of Heliothis armigera (Hüb.) on chickpea. Giornale Italiano di Entomol. 4:223228.

Qayyum A and Zalucki M. P (1987) Effects of high temperature on survival of eggs of Heliothis armigera (Hubner) and $H$. punctigera Wallengren (lepidoptera: noctuidae). Journal of Australian Entomological Society. 26: 295-296.

Shah Z. A. and Shahzad M. K (2005) Fluctuation patterns of different developmental stages of Helicoverpa armigera (Lepidoptera: Noctuidae) on chickpea (Cicer arietinum) and their relationship with the environment. Entomol. Fennica 16: 201-206.

Shankar M., Munghate R.S., Babu T.R., Sridevi D and Sharma H.C (2014) Population density and damage by pod borers, Helicoverpa armigera and Spodoptera exigua in a diverse array of chickpea genotypes under natural infestation in the field. Indian Journal of Entomology, 76(2): 117-127.

Sharma H. C (2010a) Global Warming and Climate Change: Impact on Arthropod Biodiversity, PestManagement, and Food Security. In: National Symposium on Perspectives and Challenges of Integrated Pest Management for Sustainable Agriculture, 19-21 Nov 2010, Solan.

Sharma H.C (2005) Heliothis/Helicoverpa Management: Emerging Trends and Strategies for Future Research. New Delhi, India: Oxford and IBH, and 
Science Publishers, USA. 469 pp.

Sharma H.C (2012b) Effect of global warming on insect - host plant environment interactions. In: 24th International Congress of Entomology, 19-24 Aug 2012, Daegu, South Korea.

Sharma H.C., Pampapathy G., Lanka S.K and Ridsdill-Smith T.J (2005b) Antibiosis mechanism of resistance to pod borer, Helicoverpa armigera in wild relatives of chickpea. Euphytica. 142: 107-117.

Singh S.S and Yadav S.K (2006) Evaluation of chickpea varieties for their resistance against gram pod borer, Helicoverpa armigera. Indian Journal of Entomology. 68 (4): 321 - 324.

Srinivas P. R. and Jayaraj S (1989) Record of natural enemies of Heliothis armigera from Coimbatore district, Tamil Nadu. Journal of Biological Control. 3: 71-72.

Thakur J. N, Singh J. P. Verma O. P and Diwakar M. C (1995) Bioecological studies on gram pod borers Heliothis species under Jammu conditions. Journal of Advanced Zoology. 16: 118 122.

Tripathi S. R and Sharma S. K (1985) Population dynamics of Heliothis armigera (Hübner) (Lepidoptera Noctuidae) on gram in the Terai belt of
N. E. Uttar Pradesh. Giornale Italiano di Entomol. 2: 347-353.

Ugale T.B., Toke N.R and Shirsath M.S (2011) Population dynamics of gram pod borer, Helicoverpa armigera (Hubner). International Journal of Plant Protection. 4 (1) : 204-206.

Upadhyay V.R., Vyas H.N and Sherasiya R.A (1989) Influence of weather parameters on larval population of Heliothis armigera (Hubner) on ground nut. Indian Journal of Plant Protection. 17(1) 85- 87.

Yadav S.S., Kumar J., Yadav S.K., Singh S., Yadav V.S., Turner N.C and Redden. R. (2006) Evaluation of Helicoverpa and drought resistance in desi and kabuli chickpea. Plant Genetics Resources. 4: $198-203$.

Yadava C. P. and Lal S. S (1988) Relationship between certain abiotic and biotic factors and the occurrence of gram pod borer, Heliothis armigera (Hbn.) on chickpea. Entomon 13: 3-4.

Yadava C. P., Lal S. S., Ahmad R and Sachan J. N (1991) Influence of abiotic factors on relative abundance of pod borers of chickpea (Cicer arietinum). Indian Journal of. Agricultural Sciences. 61: 512-515.

\section{How to cite this article:}

Pavani, T., T. Ramesh Babu, D. Sridevi, K. Radhika and Sharma, H.C. 2019. Effect of Different Sowing Dates on Pest Incidence in Chickpea. Int.J.Curr.Microbiol.App.Sci. 8(09): 627-637. doi: https://doi.org/10.20546/ijcmas.2019.809.075 